\title{
Steric and Electronic Effects on Arylphosphonate Elimination from Organopalladium Complexes
}

\author{
Mark C. Kohler, Robert A. Stockland Jr., * and Nigam P. Rath
}

Department of Chemistry, Bucknell University, Lewisburg, PA 17837

Department of Chemistry and Biochemistry, University of Missouri at St. Louis, St.

Louis, MO 63121

rstockla@bucknell.edu

SUPPLEMENTAL INFORMATION

Representative ${ }^{31} \mathrm{P}\left\{{ }^{1} \mathrm{H}\right\}$ NMR spectra from thermolysis reactions 

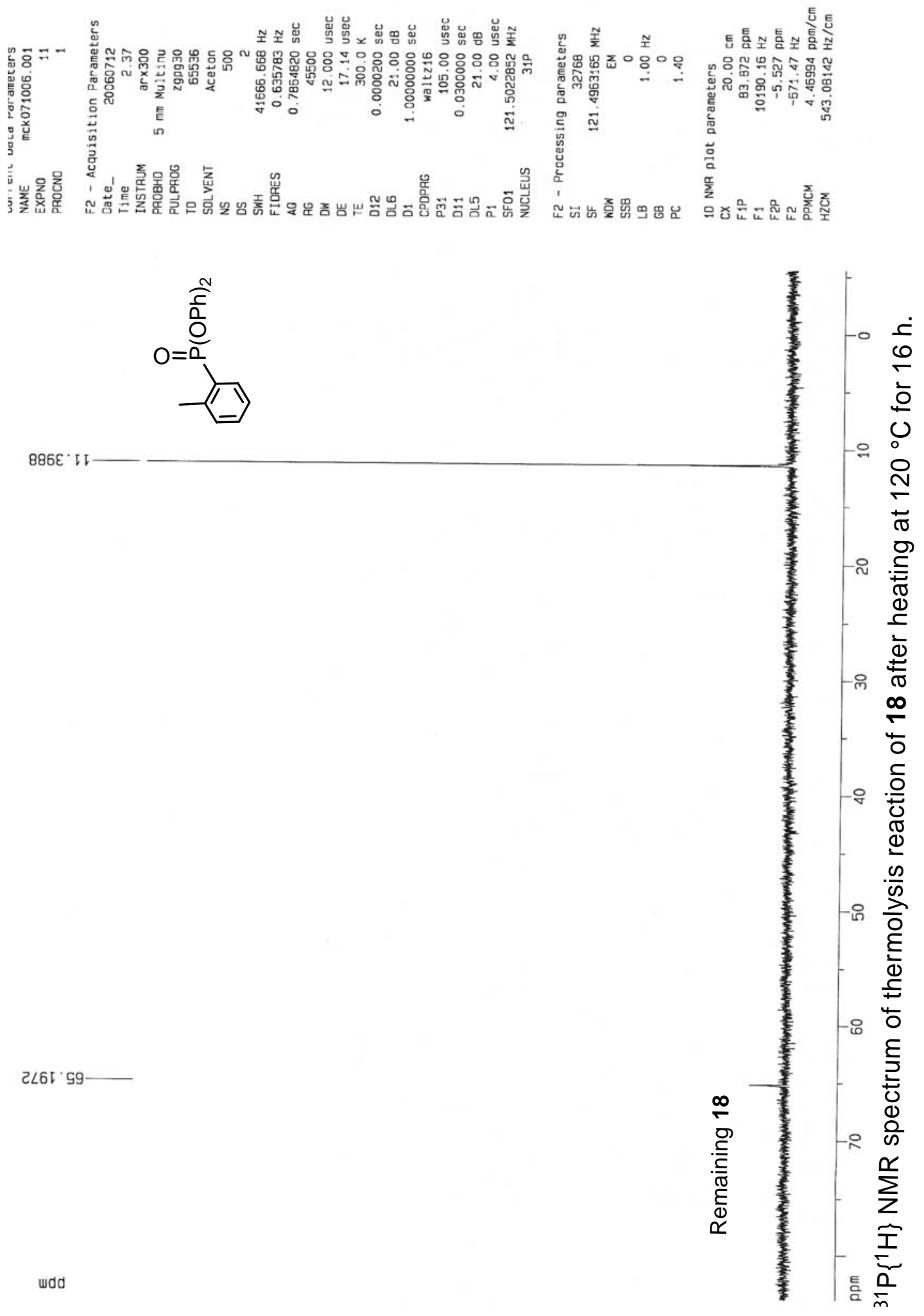

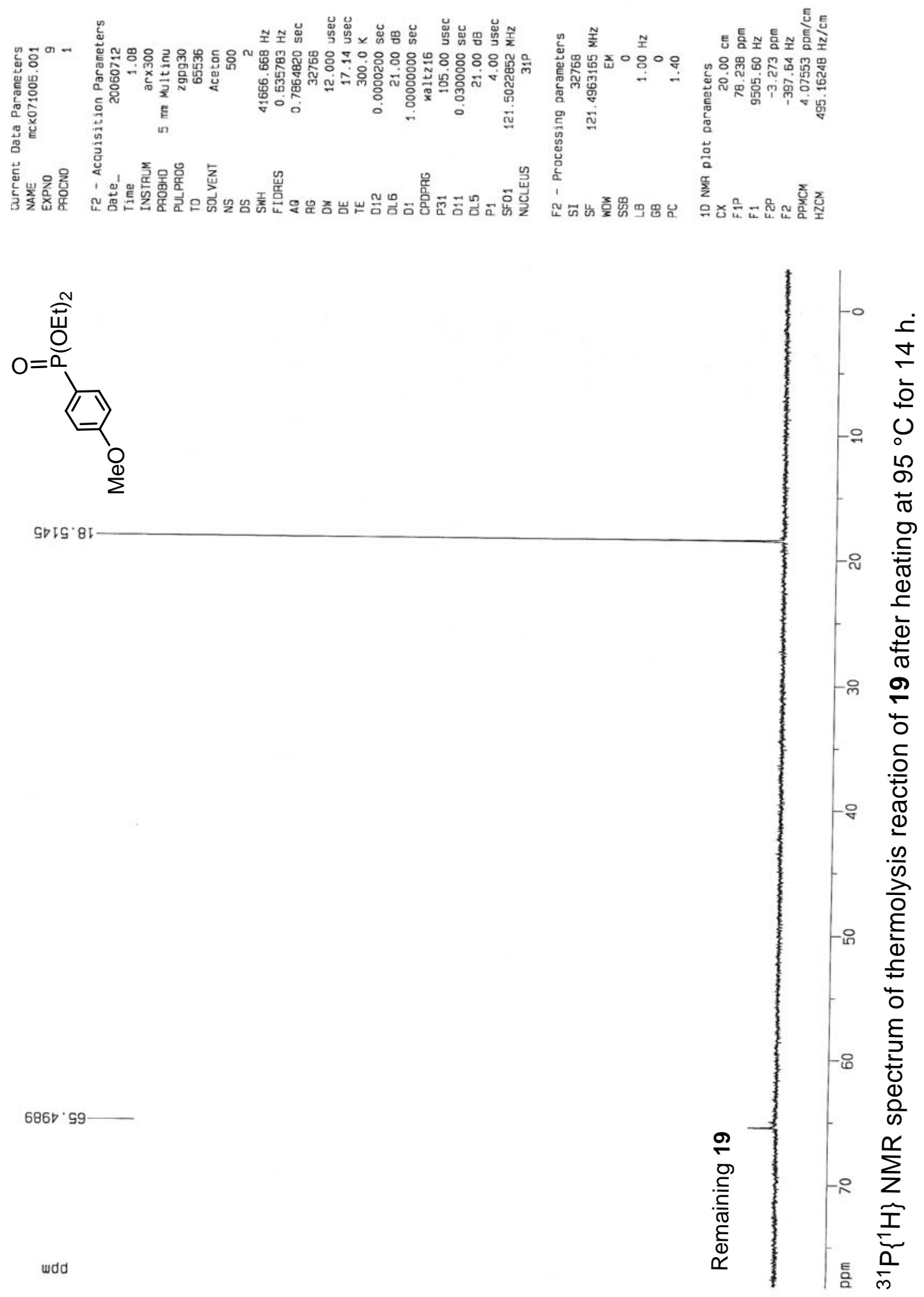

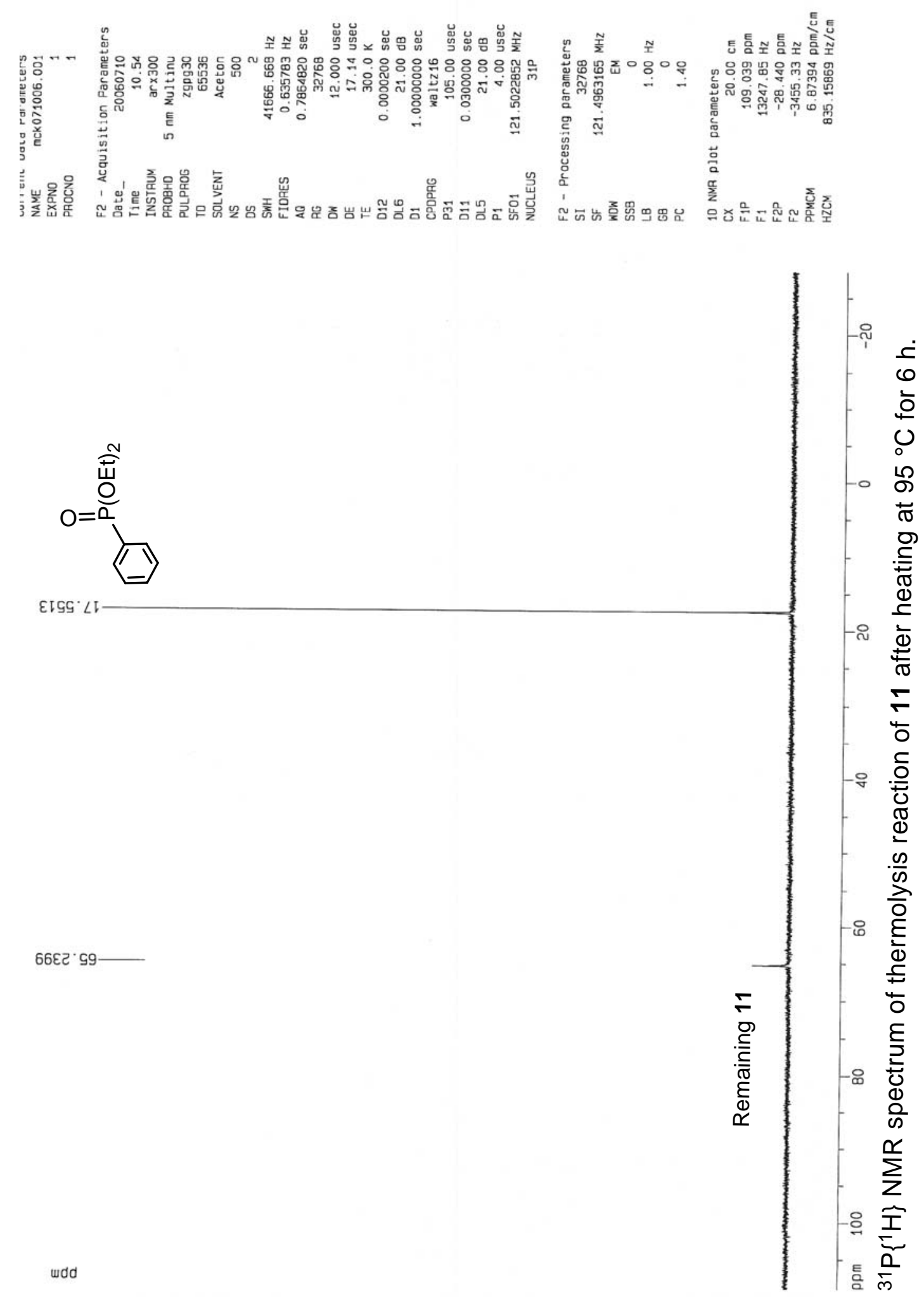

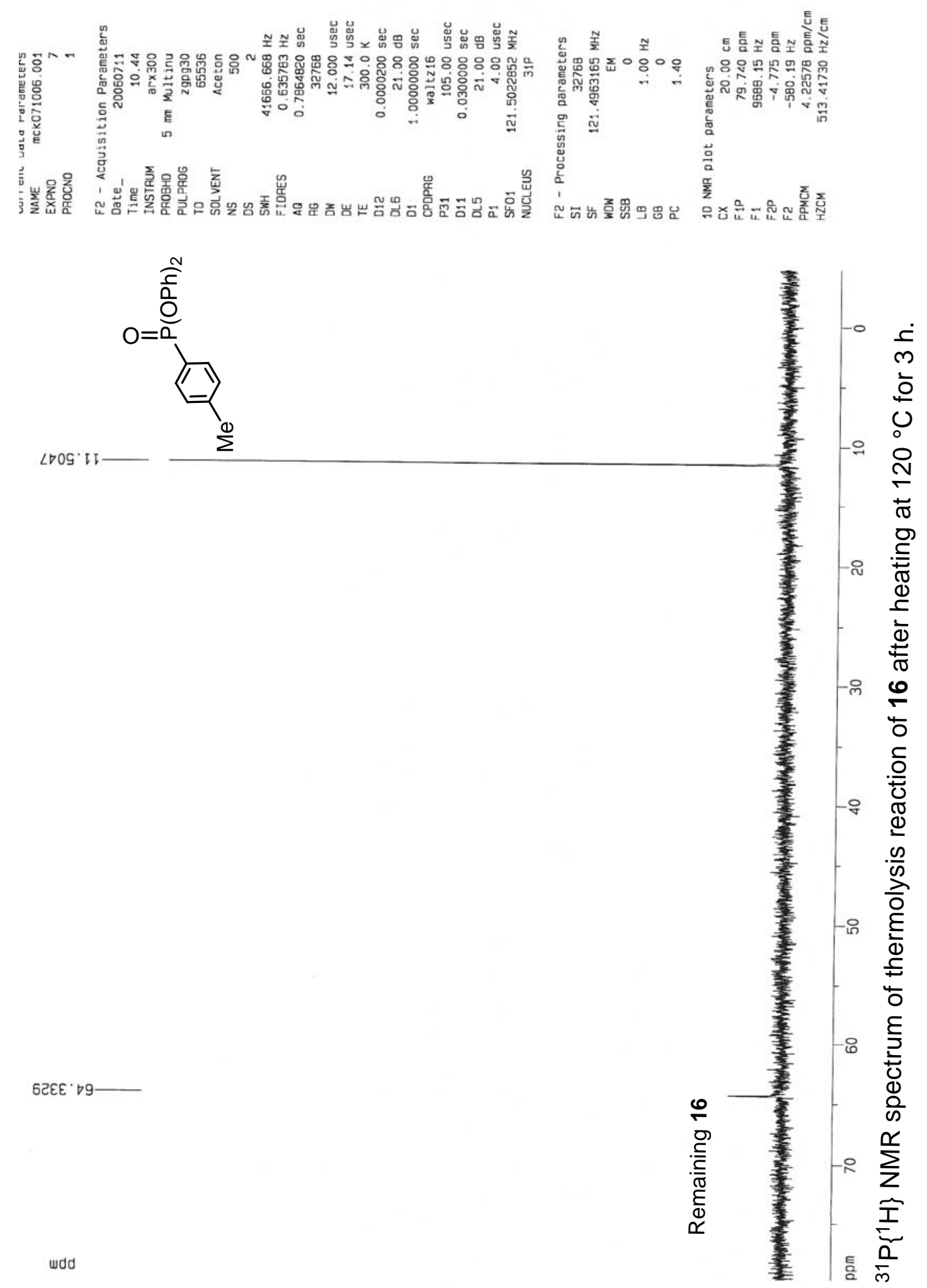

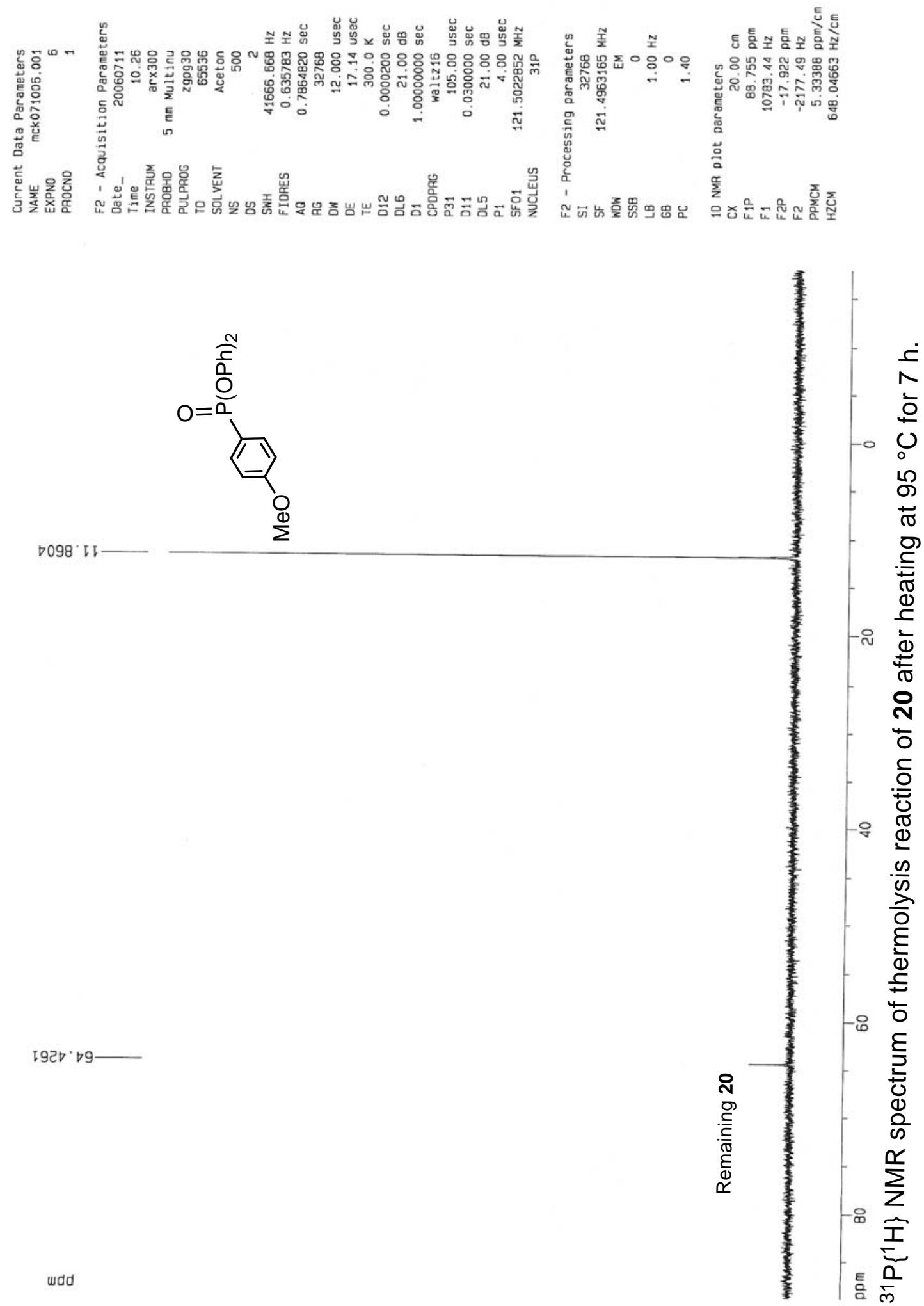